\title{
Economic Mathematic-Statistical Modeling in Distribution of Investments in Uzbekistan
}

\section{Bayhonov Bahodirzhan*}

Department of Econometrics, Tashkent State University of Economics, Uzbekistan

\begin{abstract}
The main purpose in attracting and using of investments is an achievement of leading positions in economic development and supply world's market with local products of Uzbekistan. There is no doubt that to achieve such targets needs accordance plan and forecasting based on scientific researches. Hence, here in this article were given conclusions of effective using of investments on the basis forecast related to econometrics modeling of such indexes as, GNP, basic funds, conditions of industrial investments, also, inflation rates and employment in the country.
\end{abstract}

Keywords: Economic systems; GNP; Inflation rates; Model; Investments; Forecast; Extrapolation

\section{Introduction}

There is a great necessity of science based forecast of economic proceeding in elaboration of our country future documentations and development of integratons to world economy.

According reports of the First president of the Republic of Uzbekistan, I.Karimov, were said that - "there is a great necessity to forecast of organization of production process - from starting of refinement of raw materials, till getting finished product - full cycle, purposeful use of costs and levels of its cover of expenditure". Because, if we speak about full understanding of forecast, there is a necessity of full understanding and learning all its laws for better quality.

Forecasting - this is a special science elaboration, defines future development and fulfills only on the basis of science elaboration. Also, forecasting shows what can be happen in future beforehand. We need to take note, that first of all, it needs to plan all actions based on proper forecast. Hence, the planning is the most obligatory condition for fulfillment.

\section{Literature Review}

Many scientists of foreign countries conducted researches on "Investment activity" and "Marketing strategy", but they were considered only on a portfolio of securities. One of them, scientific researcher Lin Ding [1] in his paper he gave the solution to the investment timing problem as a function of parameters of the model, in particular, of the tax holiday duration and interest rate for borrowing. He had studied the question whether the higher interest rate for borrowing could be compensated by tax holidays. Another researcher, Startseva [2] in her work researched a principle of reducing indeterminacy during management decision making, due to usage of additional objective information, which could be found using special diversified corporation evolution forecast economic mathematical model (EMM) was suggested. Chinese scientists Dong Jiuying and $\mathrm{Li}$ Yinsheng $[3,4]$, showed that the mathematical problem of optimally managing a portfolio of securities had received considerable research attention in recent years. Most such research had been concerned with the classical economic objective of maximization expected utility of terminal wealth and or utility of consumption over a planning horizon that could be finite or infinite. The asset appreciation rates and volatilities in all of these studies were constants, that was, the so-called "investment opportunity sets" were constants $[2,3]$.
By the idea of Xiaoqing $\mathrm{Ma}$ if there was no accurate prediction, investors not only couldn 't obtain expected profits, but also aggravated the fluctuation of macroeconomic [5].

But researches in these papers made in areas of investment timing problems and power industry investments, so they didn't learned purposes in attracting and using of investments is an achievement of leading positions in economic development.

\section{Research Methodology}

Besides, forecasting in Uzbek language means "prediction", but from our point of view, it is not allowed to consider these two expressions as the same. Because forecasting - has a probability character, with development results of objects and accidents, and its influense spheres are very wide, such as: geography, geology, ecology, economics, social, foreign political and juridical spheres and etc.

Hence, the object of this science elaboration, economic forecasting first of all is a process, which aimed to development of economic systems, through making economic forecasting based on scientific economical laws.

During getting these objectives all possible situations are forecasted. Chosen development types as the most effective, are used as information basis in creation of complex programming which could be used as necessary actions in future [6].

Further, for expanding of science plans in achievement of one in many directions of definite plan programs or the complex of programs considers through inspection. This plan gives an opportunity to choose and to prove sequence of terms of carrying out economic system actions. It is necessary to keep in mind that we use system analysis method because of complexity and large-scale of economic system (Figure 1).

*Corresponding author: Bayhonov Bahodirzhan, Tashkent State University of Economics, Department of econometrics, Uzbekistan, Tel: +998971567873; E-mail: bahodir73@mail.ru

Received June 07, 2017; Accepted July 27, 2017; Published August 07, 2017

Citation: Bahodirzhan B (2017) Economic Mathematic-Statistical Modeling in Distribution of Investments in Uzbekistan. J Bus Fin Aff 6: 281. doi: 10.4172/2167 0234.1000281

Copyright: (C) 2017 Bahodirzhan B. This is an open-access article distributed under the terms of the Creative Commons Attribution License, which permits unrestricted use, distribution, and reproduction in any medium, provided the original author and source are credited. 
Citation: Bahodirzhan B (2017) Economic Mathematic-Statistical Modeling in Distribution of Investments in Uzbekistan. J Bus Fin Aff 6: 281. doi: 10.4172/2167-0234.1000281

Page 2 of 3

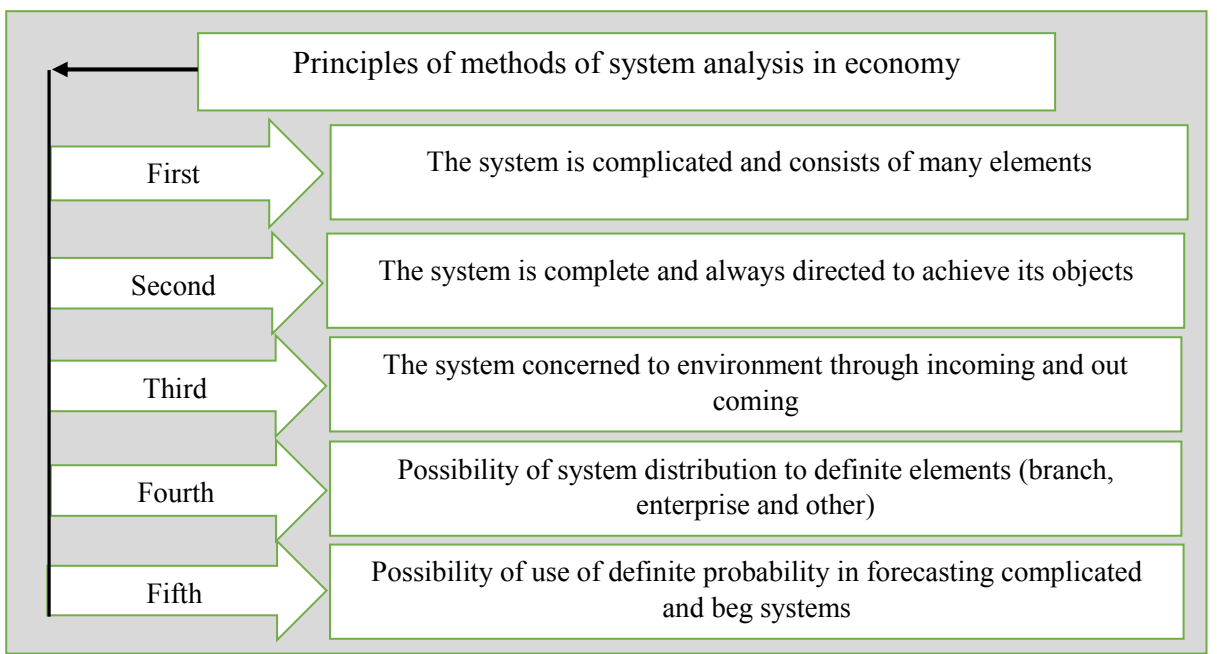

Source: author's idea

Figure 1: Principles of methods of system analysis in economy.

Hence, particular features of analysis showed on the picture, defines expediency of carrying out a number of logical stages for forecasting. Especially:

1. For object achievement we need to carry out correlation analysis and to identify interrelation.

2. Using factors identified through analysis we arrange regression equation.

3. Arranged equation being evaluated through a number of criterion such as Fisher, Student, Darbin-Watson and etc. [7].

4. If equation corresponds to all criterions, we will forecast definite index.

Hence, the above-mentioned ideas, taking into consideration of complexity of economic objects and processes, it is appropriately to use extrapolation method of forecasting on the basis of perspective development of economic objects and processes in future, which gives a chance of learning circular factors of research object.

The main reason of it, is that extrapolation method usually based on forecast of time rows, and also modelling methods of time rows, dynamic raws of economic indexes.

On the basis of above-mentioned ideas, we analyse rate of dynamic rows of GNP and future amount of production in Uzbekistan in 19952015 years, and also a number of influential factors, such as investments amount, employment level by branches, quantity of enterprises and inflation rates.

\section{Analyze results}

For proper working out of economic model of changes of production GNP of Uzbekistan under few factors influence, first of all, it needs to make analysis their correlation interconnection. According that, the chosen investments for amount of GNP $(0,998835)$, fixed funds $(0,966626)$ and changes of employed people in economy $(0,946714)$ were identified very close interconnection among them. But, the factor of inflation with GNP factor are inversely $(-0.72214)$.

As a result of our research we get many elemental model of GNP changes:
$Y=8241,7602+4,0027823 \times X_{1}+0,0374589 \times X_{2}+0,4141966 \times X_{3}-1040,622$ $\times X_{4}$

Here: $X_{1}$-investments to fixed capital;

$X_{2}$-fixed capital;

$X_{3}$-amount of employed people in economy;

$X_{4}$-inflation rate.

Now, to solve above-mentioned many elemental models, we need to arrange models related to activity of each factor and they look like:

$$
\begin{aligned}
& X_{1=} 7342,507619+2279,606786 \times t ; \\
& X_{2=} 4501,68+1637,996 \mathrm{t} ; \\
& X_{3=} 8556,989+279,7614 \mathrm{t} ; \\
& X_{4}=7,586667-0,07 \times t
\end{aligned}
$$

Then we put models of factors changes to formula (1)and make forecast by chosen factors amount.

According data on Table 1, the amount of investments to Uzbekistan economy in 2016 year is 43606.63 milliard sum and hence, when level of inflation average is $6 \%$, the amount of investments will be 1809011.6 milliard sum, which in comparision with 2015 year has growth of $7.8 \%$.

To 2020 year expected amount of investments to fixed capital will be 54928,6 sum, under consistent, steadily carrying out of reforms by modernization and diversification of economy in 2015-2019 years, amount of GNP will be expected 229920.7 milliard sum. Such situation means that in comparison with 2015 year, will be to 58551.7 milliard sum and growth to $26.6 \%$ with $6.0 \%$ of inflation rate.

Of course, achievement of such positive growth 31534.2 milliard sum, can be explained as an amount of fixed funds and rate of employment 14711.7 thousand people. This situation in comparison with last year will be expressed as $27.4 \%$ and $12.7 \%$ correspondingly. Besides, we mean development of consistent carrying out reforms in every branch, their unity in economic partnership. Because, in such a difficult situation nowadays, it is necessary to refuse old views and 
Citation: Bahodirzhan B (2017) Economic Mathematic-Statistical Modeling in Distribution of Investments in Uzbekistan. J Bus Fin Aff 6: 281. doi: 10.4172/2167-0234.1000281

Page 3 of 3

\begin{tabular}{|c|c|c|c|c|c|}
\hline Year & $\begin{array}{c}\text { GNP amount } \\
\text { (milliard. sum) } Y\end{array}$ & $\begin{array}{l}\text { Investment to fixed capital } \\
\text { (milliard. sum) }\end{array}$ & $\begin{array}{l}\text { Fixed capital } \\
\text { (milliard. sum) }\end{array}$ & $\begin{array}{l}\text { Total amount of employed } \\
\text { people (thousand. sum) }\end{array}$ & $\begin{array}{l}\text { Inflation rate } \\
\text { in } \%\end{array}$ \\
\hline 2016 & 183098.3 & 43606.6 & 24982.3 & 13592.7 & 6.12 \\
\hline 2017 & 194803.9 & 46437.1 & 26620.2 & 13872.5 & 6.05 \\
\hline 2018 & 206509.5 & 49267.6 & 28258.2 & 14152.2 & 6.01 \\
\hline 2019 & 218215.1 & 52098.1 & 29896.2 & 14432.0 & 5.9 \\
\hline 2020 & 229920.7 & 54928.6 & 31534.2 & 14711.7 & 5.84 \\
\hline
\end{tabular}

Source: Author's working out of based on data of Uzbekistan Statistics Committee

Table 1: Amount of GNP forecast in Uzbekistan.

\begin{tabular}{|c|c|c|c|c|c|}
\hline Year & $\begin{array}{l}\text { Gross volume of industrial } \\
\text { products, } \mathrm{Y} \text { (milliard. sum) }\end{array}$ & $\begin{array}{l}\text { The volume of investment } \\
\text { (milliard. sum) } X_{1}\end{array}$ & $\begin{array}{l}\text { Amount of employed } \\
\text { people } X_{2} \text {, thousand }\end{array}$ & $\begin{array}{c}\text { Amount of enterprises } X_{3} \text {, } \\
\text { thousand }\end{array}$ & Inflation rate, $X_{4}$ \\
\hline 2015 & 91708.1 & 13168.4 & 1664.7 & 1681.6 & 6.12 \\
\hline 2016 & 96474.3 & 13932.0 & 1698.3 & 1714.9 & 6.05 \\
\hline 2017 & 101240.6 & 14695.6 & 1731.8 & 1748.1 & 6.01 \\
\hline 2018 & 106006.8 & 15459.2 & 1765.4 & 1781.4 & 5.9 \\
\hline 2019 & 110773.1 & 16222.8 & 1799.0 & 1814.6 & 5.84 \\
\hline 2020 & 115539.3 & 16986.4 & 1832.5 & 1847.8 & 5.8 \\
\hline
\end{tabular}

Source: Author's working out of based on data of Uzbekistan Statistics Committee

Table 2: The forecast of expected volume of gross product of industry of Uzbekistan (taking into consideration all factors).

inertial methods of development for further prevention of rapid decrease of demand and keeping uncertainty in world market.

During present conditions of globalization all over the world, one of the main tasks of our government is to steadily technical and technic renovation of production, steadily looking for internal opportunities and reserves, based on deep structural changes in economy, which means full development of industrial sphere. For this purpose, it is necessary to repeat by degrees all processes of forecasting of Uzbekistan's GN volume.

The factors influencing to production branches of:

$X_{1}$-investment involved with industry, $X_{2}$ - an amount of employed people to industry, $X_{3}$ - an amount of functioning enterprises in industry, and $X_{4}$ - rate of inflation.

Based on these determinations we work out economic models satisfying changes of factors related to time term. According them:

$X_{1=}-2867,28+763,603 t ;$

$X_{2=} 960,1316+33,55263 \mathrm{t}$;

$X_{3=} 983,5737+33,2406 \mathrm{t}$;

$X_{4}=7,586667-0,07 \times t$;

Through above-mentioned models, using the method of insertion instead of $X_{1}, X_{2}, X_{3}, X_{4}$ factors, we identify the results of expected amount of products of industry sphere in Uzbekistan.

$Y=-3661,32839+4,80186504 \times X_{1}-257,9451398 \times X_{2}+292,3053756$

$\times X_{3}+313,50498 \times X_{4}+8241,7602$

Then, we insert expressions and get the results, which should be written into the table.

According the data on Table 2, the growth of functioning enterprises of industry sphere in 2016 year is $2 \%$ and it will come in total 1714,9 thousand, amount of employed people in industry reached to 1689,3 thousand people and volume of expected investment in compassion with 2015 year has grown to $5,8 \%$ and it is 13932,0 milliard sum, expected volume of gross industrial product will come to 96474,3 milliard sum.

\section{Conclusion}

Be the reason of consistent carrying out the Program of industrial development in 2015-2019 years, we can predict that to 2020 year the volume of attracted investment to industry will be 16986,4 milliard sum, in comparison with 2015 year the growth of employment will be $101 \%$ and the growth of full amount of enterprises will be $9,9 \%$, the volume of industrial products production will be 115539,3 milliard sum and it will be $26 \%$ more than in basis year.

Hence, of this research we can make following conclusions, taking into consideration the objects of such theme and complexity of economic processes. It is necessary to use extrapolation method based on perspective development of economic laws in future, which gives an opportunity to learn cycle factors of research object, based on invariability. The reason of it is that extrapolation method usually based on forecast of single size time index, and also based on method of single size time index modeling, single size time index dynamics and single size time index at all.

\section{References}

1. Ding L (2008) Research on Analytical Model of the Risk-Based Economic Evaluation. Wireless Communications, Networking and Mobile Computing, 4th International Conference, WiCOM '08.

2. Startseva AA (2004) Diversified corporation evolution forecast economic mathematical model. The 8th Russian-Korean International Symposium.

3. Yinsheng Li (2010) An empirical research on R\&D investment and economic growth. 2nd International Conference, Information Science and Engineering (ICISE)

4. Jiuying D (2007) Optimal Investment Consumption Model with Vasicek Interest Rate. Control Conference, CCC.

5. Xiaoqing $\mathrm{Ma}$ (2010) Power industry investment, electricity production and economic growth in China: Relationship and forecast. Universities Power Engineering Conference (UPEC).

6. Ilichenko AN (2006) Economic-mathematic methods. Finance and Statistics, p: 223.

7. Berejnaya EV, Berejnoy VI (2005) Mathematic methods and modelling of economic systems. Finance and Statistics. 